working out simpler methods for the assessment of dangerous effects.

Following Prof. Cameron, Prof. A. Wilson discussed the chronic muscarinic, nicotinic and central effects of di-isopropyl fluorophosphonate in normal subjects and compared the effects of this substance and neostigmine in patients with myasthenia gravis and the changes accompanying these effects in the cholinesterase levels of blood. He reported, further, on the effects of di-isopropyl fluorophosphonate on the central nervous system of normal subjects and of patients with functional psychoses. Dr. L. Bidstrup and Dr. J. A. Bornell then gave a detailed description of the paralysis which occurs in patients poisoned by the two cholinesterase-inhibitors triorthocresyl phosphate (TOCP) and bis (monoisopropylamine) fluorophosphine (mipafox).

Poisoning by triorthocresyl phosphate has been known for many years and was the cause of the well-known ginger paralysis which occurred in the United States of America in 1930 ; several thousand people were affected and there were some deaths. In these cases gastro-intestinal symptoms were followed after a latent interval of two to three weeks by peripheral neuritis and led in many cases to permanent disability due to lesions in the central nervous system affecting particularly the pyramidal and cerebellar tracts of the spinal cord.

In the search for new organic phosphorus compounds which would be effective as insecticides but less toxic than parathion and other related substances already in use, bis (monoisopropylamine) fluorophosphine was discovered. Three people employed on the manufacture of a small quantity of this compound by a pilot process developed the symptoms and signs of acute organic phosphorus poisoning. Two developed paralysis in the third week after the acute episode.

Both triorthocresyl phosphate and bis (monoisopropylamine) fluorophosphine are selective inhibitors of pseudocholinesterase and were found to cause demyelination; the lesions in the central nervous system of man in poisoning by the latter are confined to the pyramidal tracts, whereas in poisoning by the former the spino-cerebellar tracts are affected as well and there are lesions in the cerebellum. It is, how. ever, the opinion of Dr. Bidstrup and Dr. Bornell, based on the clinical findings and electromyographic studies in the cases of poisoning by bis (monoisopropylamine) fluorophosphine, that the central nervous system damage and peripheral nerve lesions are secondary to prolonged failure of conduction at the neuromuscular junctions.

The demyelination was discussed in detail by the next speaker, Dr. F. A. Denz, who reported on these pathological changes in peripheral nerves and in the central nervous system in various species. The tracts affected vary in different species. The lesions were obtained with triorthocresyl phosphate, diisopropyland diethyl-fluorophosphonate and with bis (monoisopropylamine) fluorophosphine. The problem was discussed whether the primary effect is on the myelin sheath or on the axon, and why some tracts are affected and others not. In the chicken the $\operatorname{sam} \theta$ tracts are involved as in beriberi. Closely connected with this problem were the following contributions given by Prof. R. H. S. Thompson and Dr. A. N. Davison. Prof. Thompson showed that the paralysis produced by triorthocresyl phosphate is not due to inhibition of true cholinesterase at the motor endplate, as originally suggested by Bloch. The demyelination can also not be fully explained by inhibition of pseudocholinesterase, because when using other selective inhibitors of this enzyme (for example, isooctamethylpyrophosphoramide), although inhibition of the central nervous system of the experimental animals was as strong as after triorthocresyl phosphate, demyelination did not occur. Similarly, Dr. Davison, based on his results obtained with cholinesterase-inhibition of the central nervous system of birds by triorthocresyl phosphate, bis (monoisopropylamine) fluorophosphine and isooctamethylpyrophosphoramide, came to the same conclusion that prolonged inhibition of pseudocholinesterase does not appear to be a prerequisite for demyelination. Complete inhibition and subsequent fast recovery of the cholinesterase activity could be produced by the demyelinating compounds triorthocresyl phosphate and bis (monoisopropylamine) fluorophosphine, as well as by the non-demyelinating compound isooctamethylpyrophosphoramide. Judged by their effects on the pseudocholinesterase of the central nervous system, these compounds are apparently indistinguishable. Triorthocresyl phosphate is different in that it produces a prolonged fall in pseudocholinesterase activity. It also differs, together with isooctamethylpyrophosphoramide, in not producing any acute symptoms during the first few days after injection. Furthermore, it has not been possible to produce paralysis in the rat, despite prolonged and complete inhibition of pseudocholinesterase. The mechanism underlying demyelination thus remains obscure; but it is interesting and probably significant that, so far, only selective inhibitors of pseudocholinesterase have produced such late lesions in the central and peripheral nervous system.

In the subsequent discussion Dr. G. S. Hartley pointed out that the two organo-phosphorus compounds with which the late development of paralytic effects has been most clearly established are at opposite ends of the scale of water- and oil-solubility. $B i s$ (monoisopropylamine) fluorophosphine is the most completely water-favourable of all the compounds examined, and triorthocresyl phosphate the most completely lipophilic. Dr. Aldridge's indication that the latter substance is first converted by the body into another compound may throw some light on this apparent anomaly. Prof. Biggart's closing remarks dealt with the medical and pathological aspects of the anticholinesterases, and he pointed out some of the pertinent, unsolved problems.

\section{RATIONS FOR LIVESTOCK IN BRITAIN}

$T$ HE Scottish Group of the Nutrition Society organized a conference on "Problems in providing Rations for Britain's Livestock", which was held in Aberdeen, centred on the Rowett Research Institute, during October 1-2. Prof. R. G. Baskett was in the chair, and papers were read by J. N. Aitken, A. S. Barker, S. Bartlett, K. J. Carpenter, J. A. Crichton, J. Duckworth, A. Eden, W. S. Ferguson, W. Holmes, H. R. Humphries, W. R. Muir and K. L. Robinson.

The time of the conference was opportune, for domestic and foreign trade in feeding stuffs and compounds has largely passed out of the control of the Ministry of Food and back to the hands of 
private traders. The Ministry's regulations no longer control the types of feeding compounds that can be manufactured or the kinds and amounts of ingredients that can be included. In addition, the use of certain antibiotics as growth stimulants in stock feeding has recently been legalized.

Circumstances have changed since farmers and compounders were last free to buy feeding stuffs and to use their skill and experience to combine them into balanced rations for farm stock. Since then the feeding stuffs moving through the channels of international trade have changed in volume, supplies of some remaining abundant, supplies of others being greatly diminished. Even trading in exportable surpluses that are plentiful is not free from difficulty, since the official policies of foreign countries burdened with these commodities are not materially affected by relaxation of controls in Britain. Such problems that faced the Ministry of Food have not disappeared with the return of trade to private hands.

The pattern of Britain's agriculture has changed since pre-war days. With more intensive use of land and greater domestic production of feeding stuffs, with greater numbers of livestock and their greater reliance on home-grown feeds, many feeding problems are different from those before the War. But none of these problems has been neglected. After the first abrupt changes in 1939 other changes came gradually, and as problems have become apparent research has developed in directions dictated by them.

Early in the conference the trends in supplies of feeding stuffs in the international markets were examined. Supplies of cereals are good and likely to continue to be reasonably plentiful. Supplies of protein concentrates are poor, and likely to remain so. Emphasis was rightly placed on the limitations of current knowledge about the nutritive values or feeding potentialities of many protein-rich plant by-products, it being recognized that scientific knowledge is extensive only so far as soya bean and groundnut meals are concerned.

Emphasis was placed on the contribution that grass and grassland products can make to solving present and future feeding problems. Grass is the most important single crop in Britain, already providing between 65 and 70 per cent of the energy needed by the nation's livestock together with important amounts of protein, while remaining the cheapest source of these nutrients. There remain great opportunities for increase in grass yield per acre on many farms.

It was recognized that mastery over grass production is easier to attain than efficient use of the crop as it grows in the field. The first step towards greater efficiency is the correct combination of strip grazing of properly manured grass (the herd being restrained by electric fencing) with conservation of the excess grass for winter feeding. By full exploitation of grass throughout the year, important quantities of feed, and especially of protein concentrates, can be saved in the dairy herd. These are then available for pigs and poultry.

Difficulties in such intensified management of grass were frankly stated. Most important of all is the effect on farmers and farm workers of the monotonous nature of daily work on a dairy farm based on high grass production. Also, various diseases appear to be closely linked to the feeding of young, highly nutritious grass, although they can be largely controlled by careful management. Again, in some areas, grass is not a reliable crop, whereas in others it offers to farmers a greater security against adverse weather.

In addition to the savings in concentrates that the greater use of grass permits in the milking herd, the prospects of economy in rearing replacements for the herd were also examined. Special attention was given to the results now coming forward from studies of one-egg twin heifers reared on different planes of nutrition. In spite of the slow growth they permit, low planes of rearing have practically no influence on final size at maturity; and although the onset of first ostrus is delayed by about three and a half months, subsequent fertility is not affected. On changing animals from a low plane of rearing to a high plane, there is a rapid increase in growth-rate, and heifers reared on low planes of nutrition gain rapidly in weight during the first lactation. Milk yields of animals reared on low planes of nutrition are somewhat lower in the first lactation, and to a lesser extent in the second. Economy in costly winter feeding can be practised with safety, provided that good summer grazing is available; but if heifers are to be bred in mid-winter to calve the following autumn, it may be necessary to provide a generous winter ration to ensure early fertility.

Economies in the feeding of pigs and poultry were seen as a problem in securing a more efficient use of protein concentrates, and particularly in devising rations that would allow the deflexion of scarce and costly animal by-products to those animals that need them most : to breeding stock and young stock. It is now possible, without using any supplements of the 'animal protein factor', to make rations exclusively from plant sources that will meet all the needs of pigs from $90 \mathrm{lb}$. live weight to bacon weight and of birds throughout the laying year, provided the eggs are not to be used for hatching. Under British conditions it is much less difficult to meet the needs of these stock for vitamin $B_{12}$ than for riboflavin, widespread deficiency of riboflavin existing in many flocks of breeding birds. Small economies can be made in the use of feeding stuffs in rearing bacon pigs by following a system of restricted feeding; but such savings are made largely at the expense of prolonged rearing times-that is, at the cost of greater labour and overhead charges. Only limited savings of concentrates could be made by the use of herbage in feeding bacon pigs.

Stress was placed on the need for more information about the energy that common feeds can provide for poultry and about many protein concentrates used in practical pig and poultry rations. As a guide to the energy value of feeds, the crude fibre-content is known to be unreliable; but little research is directed to finding analytical methods that will give a better prediction of the amount of energy that nonruminants can extract from feeds and put to productive use. More active research is developing in the field of assessing the supplementary value of protein-rich concentrates in rations, and this is leading to a better understanding of the nutritive value of traditional protein sources. Less-known products, such as the meat meal, grax and condensed solubles, produced by the Antarctic whaling industry, are under special study, not only to determine the value of existing products but also to aid in the improvement of whale processing on factory ships and at shore stations so that minimal damage is done to this important source of extra protein for pig and poultry feeding. 
The stimulation of growth and the savings in feed that are the possible results of fortifying a ration with antibiotics were also discussed. The picture continues to be indistinct. Where a condition exists for an antibiotic to exert a therapeutic effect, a spectacular result will be observed. In carefully controlled experinents small advantages will usually be found. In practical trials on farms the response to antibiotics is extremcly variable, but farmers may choose to pay for the safeguard that an antibiotic can give.

The conference concluded with a discussion of the role of the agricultural adviser who links the research worker and the practical farmer. There was frank recognition of difficulties that must continue to face those whos task it is to translate the new findings of research stations into profitable practices on the farms in Britain, where the farming systems are so diversified.

JOHN DUCKWORTH

\section{MIXING OF THICK LIQUIDS, PASTES AND SLURRIES}

$\mathrm{N}$ a recent report of the Committee on Chemical Engineering Research of the Department of Scientific and Industrial Research, it was pointed out that the general subject of mixing is one which would profit by more fundamental research. Although the mixing of thick materials is a matter of considerable industrial importance, there is virtually no basic information about such mixing problems, and most mixing machines have been designed by intuition and the use of empirical methods. On September 25 the British Society of Rheology organized in London a symposium on the "Mixing of Thick Liquids, Pastes and Slurries", in the hope of collecting what information is available and of clarifying the more important scientific aspects of the subject.

The symposium was opened by Mr. P. V. Danckwerts (Department of Chemical Engineering, University of Cambridge) with a paper on "General Aspects of Mixtures and Mixing". This excellent introduction to the subject first considered how the extent of mixing could be measured quantitatively. For this purpose Mr. Danckwerts introduced the concept of a 'scale of scrutiny', which he applied to the minimum size of the regions of segregation in the mixture which would cause it to be regarded as imperfectly mixed for specific purposes. The goodness of mixing could be characterized by two factors: the 'scale of segregation' is a measure of the size of the regions of segregation, or 'clumps' of the unmixed components, in an imperfect mixture, while the 'intensity of segregation' is a measure of the departure of the composition from the mean value, averaged over all the points in the mixture. Some proposed experiments were described on the mixing of two differently coloured pastes, where the number of intersections per unit length appearing along a cut section of the mixed material would provide a measure of the scale of segregation. For thick pastes the intensity of segregation will be equal to unity.

Mr. Danckwerts then suggested that dimensional analysis could help considerably in simplifying the mathematical approach to mixing problems. For the mixing of two Newtonian liquids of the same viscosity, the intensity of segregation can be expressed as a function of seven variables, but by use of dimensional analysis this can be reduced to four dimensionless groupings of variables. Some of these groupings represent important properties of the state of the system, such as Reynolds, Froude and Schmidt numbers, while others can be given a physical significance such as 'number of clumps'. These concepts may be of considerable use in 'scaling up' results from models to larger mixers. When mixing liquids of unlike viscosities, many more complications are introduced, and for Bingham solids a dimensionless grouping corresponding to a 'stiffness factor' must be introduced.

Mr. E. H. Jones (British Cotton Industry Research Association) next gave a short paper on "The Preparation of Pastes of Starch and Certain Gums for use in Textile Materials". The property of 'weavability' is imparted to textile threads before weaving, by treating with a sizing solution. The amount of size taken up by the threads as they pass through the solution depends largely on the viscosity of the sizing solution, and it is important to keep this constant. The solution contains some clay as a suspension, some tallow as an emulsion and some inorganic salts as a solution, as well as gelatinized starch and gums as a colloidal suspension. At present, an attempt is being made to develop a machine which will apply a fixed weight of solids to the thread, even if the viscosity of the solution should vary.

In the first paper of the afternoon session, on "The Mixing of Wheaten Flour Doughs", Mr. S. J. Cornford (British Baking Industries Research Association) reviewed the literature on this subject and considered how the mixing characteristics of flour doughs can be used to predict the suitability of a flour for breadmaking. The effect of mixing on flour doughs depends partly on the atmosphere in which the mixing is carried out, as the mechanical effect is modified by air inclusion and oxidation during mixing. Three factors contribute to the resistance encountered during mixing: mechanical resistance, protein swelling and sticking. The peaks in the mixing curve due to these causes do not necessarily coincide, and it is possible for some agents to affect one peak without affecting the others.

A paper by Mr. D. C. Broome (Limmer and Trinidad Lake Asphalt Co.) was read in his absence by Mr. A.E. Howes. Although mixing of thick materials is such an important technical matter to the asphalt industry, there has been little improvement in its mixing machines during the past halfcentury. Some progress is now being made, and a continuous mixer for bituminous road-mixes has been introduced in the United States. In Britain an improved type of 'whirlpool mixer' has recently been developed, and this enables mixing to be carried out in a considerably shorter time than with the older types of mixer. An 'impactor' type of mixer has also been reported from Germany.

A paper from the Road Research Laboratory, West Drayton, submitted by Dr. A. R. Lee, was read in three parts by members of the Laboratory staff. Mr. K. E. Clare gave an account of the problems involved in mixing soil and cement when making special types of road. One of the main difficulties is segregation during in situ mixing due to the greater density of the cement, resulting in a low concentration of cement at the upper surface of the road.

Mr. F. N. Sparkes discussed the problems caused by the fact that engineers tend to specify concrete mixes which are 'leaner' than formerly. Such mixes 